\title{
Genotyping of urinary samples stored with EDTA for forensic applications
}

\author{
S.H. Zhang, S.M. Zhao, Z.M. Zhao and C.T. Li \\ Shanghai Key Laboratory of Forensic Medicine, \\ Institute of Forensic Sciences, Ministry of Justice, Shanghai, PR China \\ Corresponding author: C.T. Li \\ E-mail: lichengtaohla@163.com
}

Genet. Mol. Res. 11 (3): 3007-3012 (2012)

Received October 13, 2011

Accepted January 23, 2012

Published May 10, 2012

DOI http://dx.doi.org/10.4238/2012.May.10.5

\begin{abstract}
Individual identification of urinary samples is necessary when sample switching or handling are suspected during a judicial process. To improve the rate of successful genotyping of urinary samples, we examined the stability of DNA in urinary samples stored for up to 30 days. Urinary samples from 20 healthy individuals (10 males and 10 females) were stored at $-80^{\circ} \mathrm{C}$ with different concentrations of EDTA $(0,10$ and $40 \mathrm{mM})$. Urinary DNA was extracted at days $0,3,9$, and 30 after collection. The Quantifiler Human DNA Quantification Kit was used for measuring DNA concentration. Twenty STR loci were co-amplified using amelogeninspecific PCR with the Goldeneye 20A Kit. Significant differences in DNA concentration were observed between samples from females and males. In the case of female urinary DNA preservation with 10 and $40 \mathrm{mM}$ EDTA the mean detection rate reached 0.95 after up to 30 days; for the male urinary samples, the mean detection rate of urinary DNA preserved with $40 \mathrm{mM}$ EDTA was significantly higher than with $10 \mathrm{mM}$. We concluded that $40 \mathrm{mM}$ EDTA is the best concentration for preservation of the DNA in urinary samples.
\end{abstract}

Key words: Forensic genetics; Urine; EDTA; DNA genotyping 


\section{INTRODUCTION}

Urine samples are usually collected for forensic toxicology. Assessment of sample origin is necessary when sample switching or handling are suspected during criminal justice investigations. Healthy human urine samples normally contain low numbers (up to $400 \mathrm{cells} / \mathrm{mL}$ ) of epithelial cells (i.e.; renal tubular, transitional urothelial, and squamous) (Graff, 1983). Urinary DNA degrades during storage periods, however (Chen et al., 2005; Cannas et al., 2009). Therefore, urine analysis is performed only occasionally in forensic casework. The identification and individualization of urine samples does not pose a medico-legal concern, unlike that of blood, saliva, or sperm (Sołtyszewski et al., 2006).

Although the collection of urinary samples is straightforward, storage and extraction before analysis is a multistep process in forensic applications. Reports on how best to store urinary samples for identification are sparse. Cannas et al. (2009) have shown that urine preservation at lower temperatures provides better stability of urinary DNA and that either no degradation or rapid degradation occurred from days 0 to 7 followed by slight additional degradation to 28 days with ethylenediaminetetraacetic acid (EDTA), but significant differences did exist between geographically distinct sites and genders. To investigate these differences in detail, we focused on measuring the stability of Chinese urinary DNA preserved with or without EDTA for 30 days at $-80^{\circ} \mathrm{C}$.

\section{MATERIAL AND METHODS}

\section{Samples}

Medistream urine samples (about 10-12 mL/time) were collected from 20 healthy volunteers ( 10 women and 10 men) of the Chinese Han population twice in a day. The average age for male volunteers was 34.9 years (range, 27 to 48 years) and 30.5 years for females (range, 22 to 45 ). A blood sample collected from each volunteer served as a reference sample because blood is the traditional source of genomic DNA. Written informed consent was obtained from subjects before their inclusion in the study.

Aliquots $(1 \mathrm{~mL})$ of urine preserved with various final concentrations of EDTA $(0,10$, and $40 \mathrm{mM})$ were stored at $-80^{\circ} \mathrm{C}$ for various storage periods $(0,3,9$ and 30 days).

\section{DNA extraction}

Genomic DNA of blood samples was extracted using the Chelex-100 protocol (Walsh et al., 1991). The quantity of recovered DNA was determined spectrophotometrically. Urine specimens (1 $\mathrm{mL}$ ) were centrifuged at 14,000 rpm for $5 \mathrm{~min}$. The supernatant was aspirated, leaving $30 \mu \mathrm{L}$ sediment. DNA was extracted using the improved Chelex-100 and proteinase K protocol and concentrated to $20 \mu \mathrm{L}$ with a Microcon-100 device (Gene Company Limited, Shanghai, China). In this protocol, the concentrated samples are incubated at $56^{\circ} \mathrm{C}$ for $1 \mathrm{~h}$. The quantity of DNA was determined using a Quantifiler Human DNA Quantification Kit (Applied Biosystems, Foster City, CA, USA).

\section{Polymerase chain reaction (PCR) amplification and short tandem repeat genotyping}

Based on the quantitation results, DNA recovered from samples was diluted to PCR-ready 
genomic DNA. Twenty short tandem repeat (STR) loci and amelogenin were co-amplified with a Goldeneye 20A Kit (http://www.peoplespotinc.com/product/product_ge20a.html) on a GeneAmp System 9700 thermal cycler (Applied Biosystems). Polymerase chain reaction amplification was performed according to manufacturer instructions. Capillary electrophoresis was carried out using an ABI Prism 3130xl Genetic Analyzer (Applied Biosystems), and genotyping results were analyzed with the GeneMapper V3.2.1 software (Applied Biosystems).

\section{Statistical analysis}

The quantitation of fresh urinary DNA samples was repeated 3 times, and the geometric mean of mass concentrations was calculated. Exponentiated data was plotted as geometric mean $\pm 95 \% \mathrm{CI}$.

The number of STR loci in urinary DNA detected by the Goldeneye 20A system were counted and compared with reference samples. When drop-in or drop-out occurred, the data of the locus was not counted. If partial loss of heterozygosity appeared, the ratio of peak height was calculated accordingly. The formula of how to estimate the ratio was listed below (hr is the height of reference sample; hs is the height of urinary sample; Li et al., 2009). If the value of ratio was outside the range of $0.5-2$, the genotyping result of the locus was not counted.

$$
\text { ratio }=\frac{h_{r}(\text { Allele } 2) / h_{r}(\text { Allele } 1)}{h_{s}(\text { Allele } 2) / h_{s}(\text { Allele } 1)}
$$

The average number of STR loci detected and the average detection rate of STR loci in urine specimens from both genders with varying final concentrations of EDTA stored for various periods were calculated. The graphing of the distributions was performed using the GraphPad Prism v4.0 software.

\section{RESULTS}

\section{DNA mass concentration of fresh urine samples}

The baseline (day 0) of urinary DNA concentration measurement using the Quantifiler Human DNA Quantification Kit ranged from 0.10 to 4.37 ng. $\mu \mathrm{L}^{-1} .1 \mathrm{~mL}^{-1}$ in fresh urine samples. Significant differences were observed between the geometric means in females and males $(\mathrm{P}<0.0001$; Figure 1).

\section{Effects of EDTA on the average detection rate of STR loci in stored urinary DNA}

The number of STR loci in urinary DNA preserved with various concentrations of EDTA $(0,10$, and $40 \mathrm{mM})$ during varying storage periods was calculated according to the principles of genotype counting. The average number detected and the average detection rates of STR loci were calculated accordingly.

The average detection rate of STR loci in female urinary DNA without EDTA appeared to decrease rapidly from days 0 to 9 followed by a slight additional decrease until day 30; the average detection rate was 0.6000 on the 9th day. Female subjects' urine samples preserved with 10 or $40 \mathrm{mM}$ EDTA were not significantly different $(\mathrm{P}>0.05)$. Urine samples preserved with $10 \mathrm{mM}$ EDTA fit a linear correlation with $\mathrm{r}^{2}=0.9462$ (Figure 2A). 


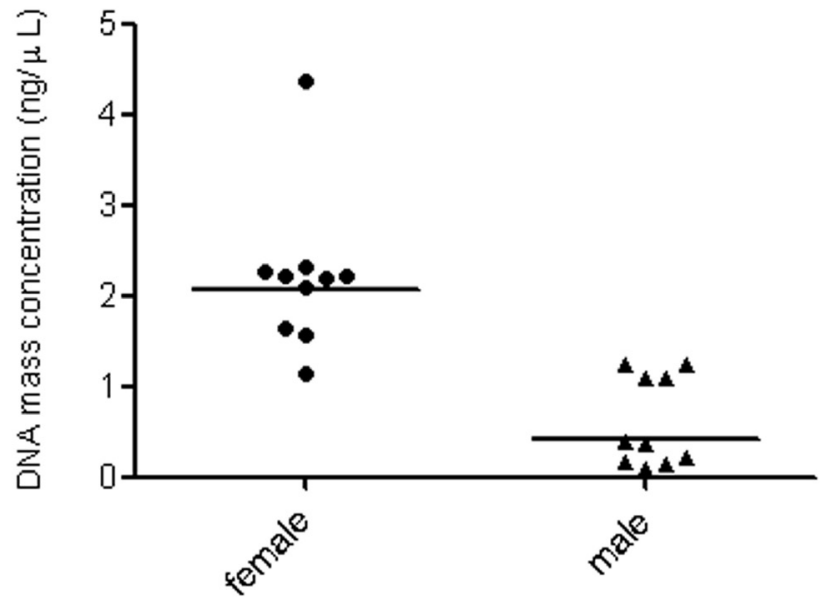

Figure 1. Baseline (day 0) assessment of urinary DNA mass concentration. Chinese males had significantly less urinary DNA at baseline than females. Scatter plot of the baseline data showing genometric mean.

A

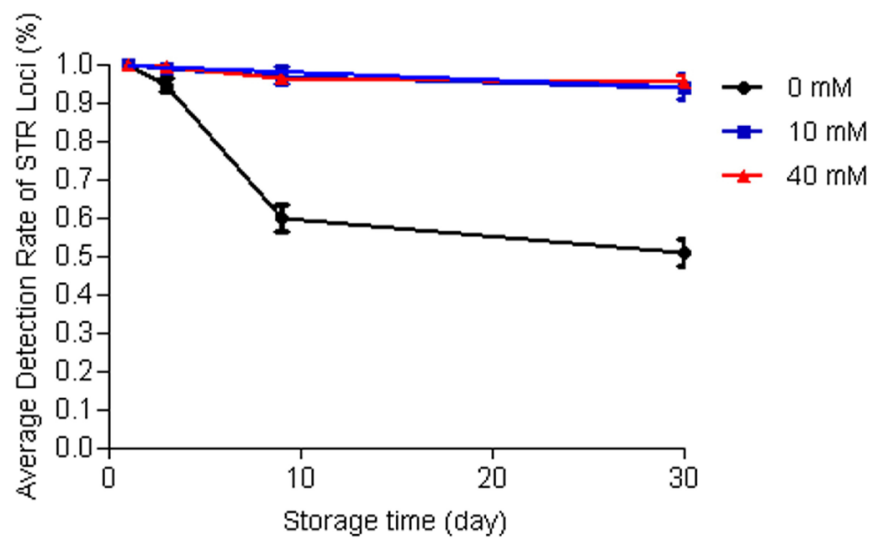

B

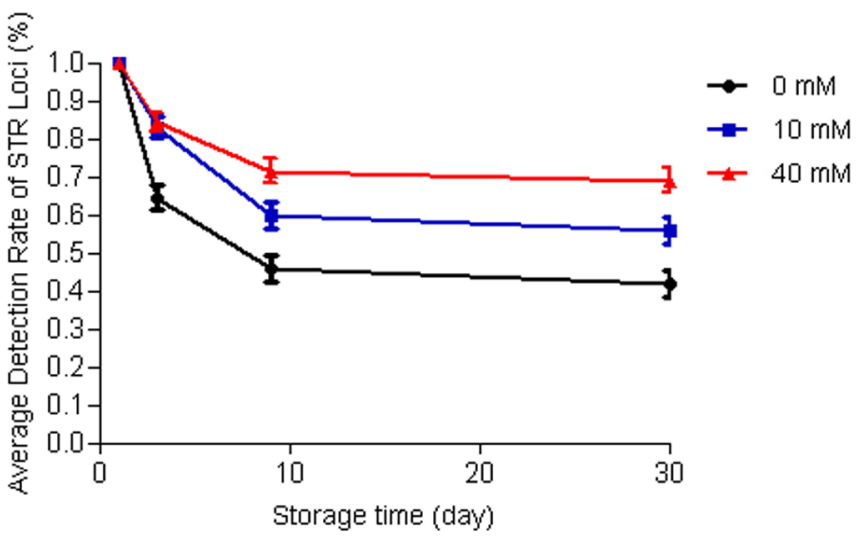

Figure 2. A. Average detection rate of STR loci of female urinary DNA preserved with different concentrations of EDTA. B. Average detection rate of STR loci of male urinary DNA preserved with different concentrations of EDTA. 
The average detection rate of STR loci in male subjects' urinary DNA without or with EDTA appeared to decrease rapidly from days 0 to 9 followed by a slight additional decrease until day 30 , but the decreases were not statistically significant $(\mathrm{P}<0.05)$. The average detection rates of male urinary DNA on the 9th day of storage were $0.4600,0.6000$, and 0.7150 when preserved with EDTA at concentrations of 0,10 , and $40 \mathrm{mM}$, respectively (Figure 2B).

\section{DISCUSSION}

Baseline assessment of the mass concentration of fresh urinary DNA showed that Chinese men had significantly less urinary DNA than Chinese women did. A similar decrease in the amount of human urinary DNA in men has been found in studies undertaken in the United States (Johnson et al., 2007), Italy (Cannas et al., 2009), and Germany (Milde et al., 1999) but was not observed in Russian (Bryzgunova et al., 2006) or Zambian (Cannas et al., 2009) populations.

Several factors are potentially important for determining the stability of human DNA in urine samples: gender, geography, addition of EDTA or Urinary Trypsin Inhibitor as a preserving solution, and storage temperature and duration. Cannas et al. (2009) discovered that only study location and the addition of EDTA correlated with urinary DNA stability. EDTA preservatives for urine are commonly prepared to a final concentration of $10 \mathrm{mM}$ using commercially available urine transport tubes sold specifically for downstream molecular analysis (Ingersoll et al., 2008). Milde et al. (1999) found that storing urine at room temperature with sodium azide for 30 days or at $-20^{\circ} \mathrm{C}$ with EDTA for 72 days provided the best protocol for the analysis of human DNA. This protocol did not stabilize urinary DNA in samples from Zambian subjects, however (Cannas et al., 2009). Clearly, the urinary DNA stability observed in one population cannot be assumed represent that of another.

We used various final concentrations of $\operatorname{EDTA}(0,10$, and $40 \mathrm{mM})$ to preserve urine at $-80^{\circ} \mathrm{C}$ in Chinese men and women. The results showed that the addition of EDTA, a polyamino carboxylic acid widely used to dissolve limescale, affected the stability of urinary DNA in the Chinese population. By adding EDTA $(10$ or $40 \mathrm{mM})$ to preserve urinary DNA from female subjects, the average detection rate of STR loci reached 0.9500 at 30 days, which is suitable for individual identification. For the urinary samples of male subjects, the average detection rate of STR loci in urinary DNA preserved with $40 \mathrm{mM}$ EDTA was higher than that with $10 \mathrm{mM}$. The results suggested that urinary sample preservation with $40 \mathrm{mM}$ EDTA is best suited for the Chinese population.

Figures $2 \mathrm{~A}$ and $2 \mathrm{~B}$ show a similar trend of average detection rate sharply decreasing from day 0 to day 9 followed by a slight additional decrease, except in female subjects' urinary DNA preserved with EDTA. What is the source of this degradation, and how can the gender differences be explained? After being bound by EDTA, metal ions remain in solution but exhibit diminished reactivity. This phenomenon suggests that the observed degradation is not due to nuclease digestion but rather to an alternative mechanism such as the eutectic phenomenon. Further studies are required to test this theory and establish whether this mechanism or others are responsible for nucleic acid degradation.

\section{ACKNOWLEDGMENTS}

Research supported by grants from the National Nature Science Foundation, China 
(\#30901701 and \#81172908), and the Nature Science Foundation of Shanghai (\#11ZR1438400).

\section{REFERENCES}

Bryzgunova OE, Skvortsova TE, Kolesnikova EV, Starikov AV, et al. (2006). Isolation and comparative study of cell-free nucleic acids from human urine. Ann. N. Y. Acad. Sci. 1075: 334-340.

Cannas A, Kalunga G, Green C, Calvo L, et al. (2009). Implications of storing urinary DNA from different populations for molecular analyses. PLoS One 4: e6985.

Chen RH, Gu LH, Ping Y et al. (2005). Study on typing of DNA extracted from urine and urine stains. Chin. J. Forensic Med. 20: 71-73.

Graff LA (1983). Handbook of Routine Urinalysis. J.B. Lippincott Co., Philadelphia.

Ingersoll J, Bythwood T, Abdul-Ali D, Wingood GM, et al. (2008). Stability of Trichomonas vaginalis DNA in urine specimens. J. Clin. Microbiol. 46: 1628-1630.

Johnson DJ, Calderaro AC and Roberts KA (2007). Variation in nuclear DNA concentrations during urination. J. Forensic Sci. 52: 110-113.

Li CT, Zhao SM, Zhang SH and Li L (2009). Evaluation of the criterion of partial loss of heterozygous in tumor tissues. Fa Yi Xue Za Zhi 25: 417-420.

Milde A, Haas-Rochholz H and Kaatsch HJ (1999). Improved DNA typing of human urine by adding EDTA. Int. J. Legal Med. 112: 209-210.

Sołtyszewski I, Pepinski W, Dobrzynska-Tarasiuk A and Janica J (2006). DNA typeability in liquid urine and urine stains using AmpFISTR SGM Plus. Adv. Med. Sci. 51: 36-38.

Walsh PS, Metzger DA and Higuchi R (1991). Chelex 100 as a medium for simple extraction of DNA for PCR-based typing from forensic material. Biotechniques 10: 506-513. 